\title{
Axial behavior of steel tube wrapped by composite as energy absorber under compressive load
}

\begin{abstract}
Beside the mechanisms such as ABS and airbag, energy absorbers are one of the most important structures which can protect occupants during impact collisions. In this paper, the purpose concerns the crashworthiness of the widely used vehicle structure, circular metallic thin-walled tubes. For improving crashworthiness parameters and using benefits of metal and composite with together, metallic tube wrapped by composite. An experimental investigation was carried out to study the energy absorption characteristics of this structure subjected to quasi-static axial loading. Different number of composite layer and fiber orientation made of E-glass direct roving and polyester resin investigated to develop the optimum structural members.
\end{abstract}

Keyword: Composite; Energy absorber; Quasi-static; Thin-walled 